\title{
Badania zmęczeniowe łącznika spawalniczego stal-aluminium z międzywarstwą tytanu
}

\author{
Fatigue testing of a steel-aluminum welding connector \\ with a titanium interlayer
}

\section{Streszczenie}

W pracy zaprezentowano wyniki badań zmęczeniowych łącznika spawalniczego stal-aluminium z międzywarstwą tytanu Grade 1. Badany materiał został poddany analizie mikrostrukturalnej. Przeanalizowano czynniki wpływające na trwałość zmęczeniową oraz zaprezentowano podstawową analizę pęknięć zmęczeniowych zaobserwowanych podczas badań.

Słowa kluczowe: zgrzewanie wybuchowe; zmęczenie; twardość; łączniki spawalnicze

\begin{abstract}
The paper presents the results of fatigue tests of a steel-aluminum welding transition joint with titanium Grade 1 interlayer. Metallic composite was subjected to microstructural analysis. Factors influencing fatigue durability were analyzed and the basic analysis of fatigue cracks observed during tests was presented.
\end{abstract}

Keywords: explosive welding; fatigue; hardness; transition joints

\section{Wstęp}

Rosnące wymagania stawiane nowym konstrukcjom inżynierskim wymuszają poprawę parametrów maszyn i urządzeń pod względem bezpieczeństwa, wydajności i kryteriów ekonomicznych. Na kształt założeń konstrukcyjnych wpływają liczne czynniki, w tym coraz istotniejsze aspekty związane z szeroko pojętą ochroną środowiska naturalnego. Jednym z czynników pozwalających na sprostanie nowym zaleceniom i normom branżowym jest m.in. wykorzystanie kompozytów oraz nowoczesnych metod łączenia materiałów konstrukcyjnych. Jedną z technologii pozwalających na produkcję materiałów kompozytowych o uniwersalnych właściwościach jest zgrzewanie wybuchowe $[1 \div 4,6,7]$. W procesie łączenia materiałów wykorzystywana jest energia detonacji ładunków wybuchowych o ściśle określonych parametrach. Technologie wybuchowe obecnie są wykorzystywane w procesie produkcji elementów aparatury procesowej i energetycznej np. ściany sitowe reaktorów [5]. Postępujący rozwój technologii zgrzewania wybuchowego powoduje stałe poszerzanie zakresu stosowania materiałów wielowarstwowych. Jako przykład może posłużyć przemysł okrętowy, gdzie kompozyty metalowe wykorzystywane są jako łączniki spawalnicze. W przypadku tego typu elementów zawierających połączenia spawane oraz złącze wykonane metodą wybuchową, zjawisko trwałości zmęczeniowej jest szczególnie istotne z perspektywy właściwości eksploatacyjnych. W literaturze specjalistycznej istnieją nieliczne opracowania dotyczące zjawiska zmęczenia materiałów platerowanych oraz łączników spawalniczych wykonanych z kompozytów wykonanych metodą wybuchową. Wymagania stawiane łącznikom spawalniczym stosowanym w przemyśle stoczniowym są określone poprzez branżowe normy

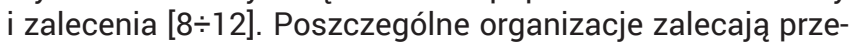
prowadzenie badań wytrzymałościowych w postaci: monotonicznej próby rozciągania, ścinania oraz odrywania złącza. Identyfikacja właściwości zmęczeniowych łączników spawalniczych jest zazwyczaj pomijana, a same testy zmęczeniowe są opisywane jedynie informacyjnie. Wyjątek stanowią standardy ABS, w których zaleca się badania zmęczeniowe o ściśle określonych parametrach $[8,10]$. Wymagania są scharakteryzowane przez kształt i wymiary próbek, poziomy obciążeń oraz oczekiwane trwałości zmęczeniowe złącza. W publikacji zaprezentowano wyniki pierwszych badań przeprowadzonych dla prototypowej konfiguracji łącznika stal-aluminium z międzywarstwą tytanu.

Dr inż. Mateusz Kowalski; inż. Amadeusz Kurek; dr hab. inż. Dariusz Rozumek, prof. PO; dr inż. Andrzej Kurek - Politechnika Opolska.

Autor korespondencyjny/Corresponding author: m.kowalski@po.opole.pl 


\section{Konstrukcja łącznika spawalniczego}

W badaniach wykorzystano łącznik spawalniczy składający się kompozytu czterowarstwowego powstałego na skutek połączenia (rys. 1): aluminium A5083 (6 mm), aluminium A1050 (1,5 mm), tytan Grade 1 (3 mm), stal S235JR+N (5 mm).

Właściwości wytrzymałościowe materiałów przed procesem zgrzewania zaprezentowano w tablicy I.

Analiza mikrostrukturalna wykazała występowanie falistego przebiegu złącza (rys. 2), które jest cechą charakterystyczną połączeń wykonanych w technologii wybuchowej.

W celu identyfikacji wpływu procesu zgrzewania na właściwości mikrostrukturalne połączonych materiałów przeprowadzono pomiar mikrotwardości w przekroju próbki (rys. 3). W porównaniu z materiałami wyjściowymi twardość po procesie zgrzewania ulega podwyższeniu. W przypadku tytanu Grade 1 mikrotwardość wzrosła o ok. $50 \mathrm{HV}_{0,5}$ w porównaniu do materiału wyjściowego.

Łącznik spawalniczy wykorzystany $\mathrm{w}$ prezentowanych badaniach został połączony z płaskownikami wykonanymi ze stali S235JR+N oraz aluminium 5083 o grubości $8 \mathrm{~mm}$. Wysokość spoiny, którą połączono płaskowniki, wynosiła min. $4 \mathrm{~mm}$ (rys. 4). Złącza spawane wykonano metodami: TIG w osłonie argonu po stronie aluminium oraz MAG w osłonie gazowej $82 \% \mathrm{Ar}$ i $18 \% \mathrm{CO}_{2}$ po stronie stali.

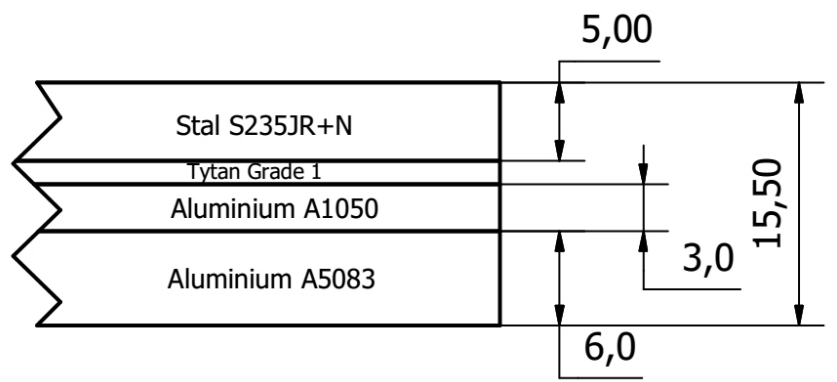

Rys. 1. Wymiary kompozytu wielowarstwowego w milimetrach Fig. 1. Multilayer composite thickness dimensions in $\mathrm{mm}$

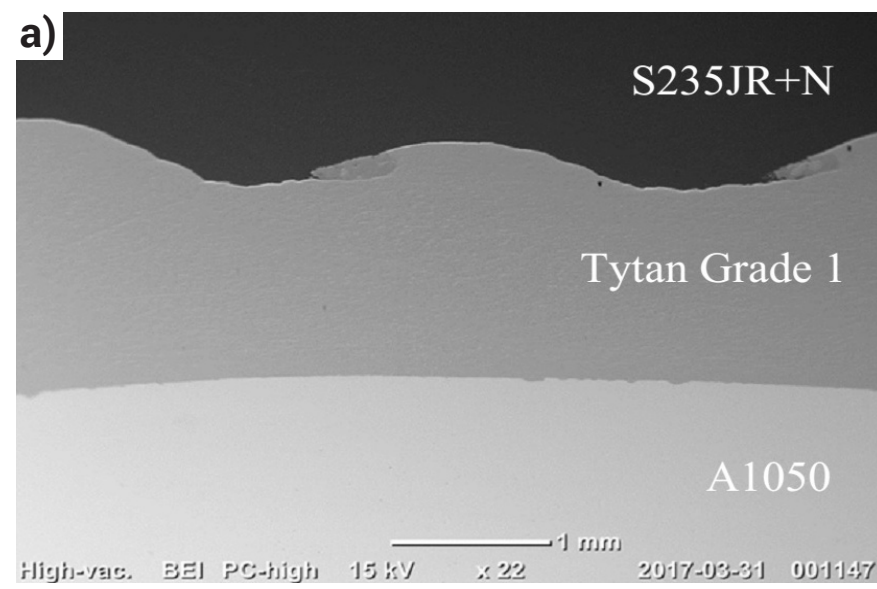

\section{Badania zmęczeniowe}

Badania zmęczeniowe wykonano zgodnie z zaleceniami ABS, na maszynie zmęczeniowej o zasilaniu hydraulicznym INSTRON 100 kN. Kształt oraz wymiary próbek zaprezentowano na rysunku 5 . Cechą charakterystyczną testów zmęczeniowych łączników jest obecność wartości średniej naprężenia nominalnego w złączu. Podczas testów

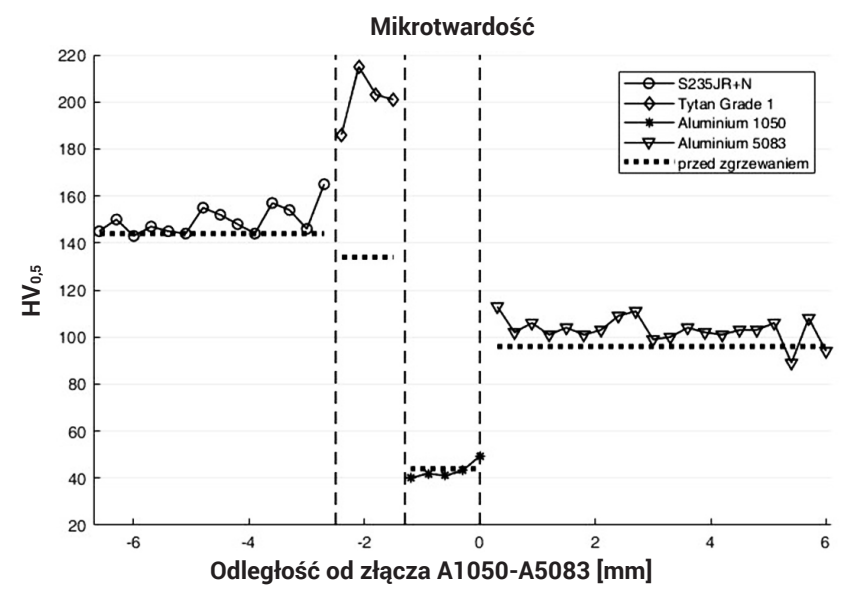

Rys. 3. Rozkład mikrotwardości w przekroju próbki Fig. 3. Microhardness thru specimen cross section

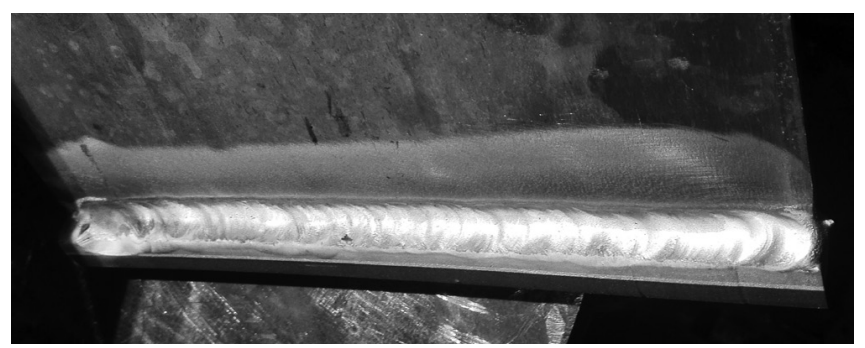

Rys. 4. Spoina po stronie aluminium

Fig. 4. Weld on the aluminum side

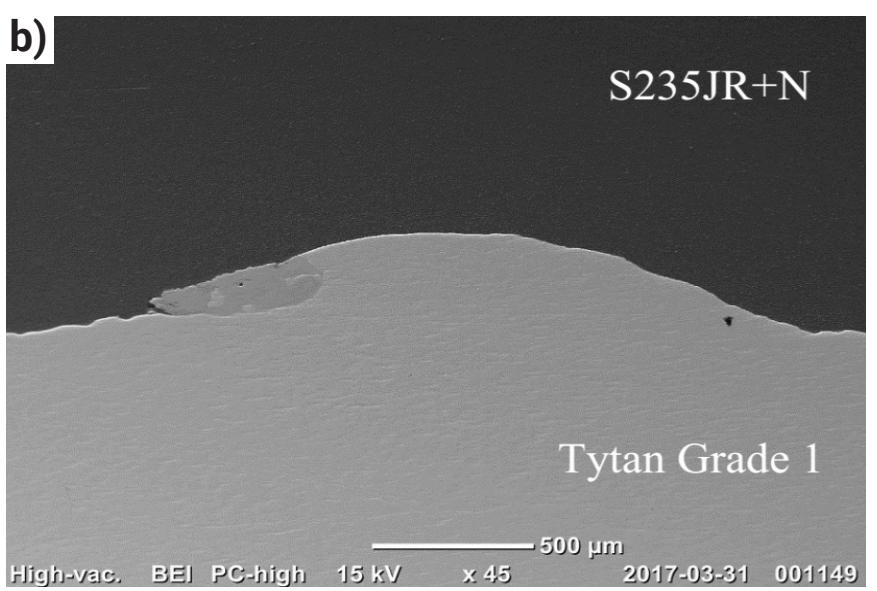

Rys. 2. Przebieg linii złącza: a) fragment połączenia stali, tytanu i aluminium, b) falisty przebieg złącza stal-tytan

Fig. 2. Interface line: a) steel, aluminum and titanium joint, b) wavy interface line between steel and titanium

Tablica I. Własności mechaniczne badanych materiałów przed połączeniem

Table I. Mechanical properties of materials before cladding

\begin{tabular}{|c|c|c|c|c|c|}
\hline \multirow{2}{*}{ Materiał } & \multicolumn{5}{|c|}{ Właściwości wytrzymałościowe } \\
\cline { 2 - 6 } & $\mathbf{R}_{\mathbf{p 0 2}, \mathbf{M P a}}$ & $\mathbf{R}_{\mathbf{m}, \mathbf{M P a}}$ & $\mathbf{E}, \mathbf{M P a}$ & $\mathbf{G}, \mathbf{M P a}$ & $\mathbf{v},-$ \\
\hline Stal S235JR+N & 235 & $350 \div 370$ & 220000 & 84000 & 0,3 \\
\hline Tytan Grade 1 & $189 \div 215$ & $308 \div 324$ & 100000 & 38000 & 0,37 \\
\hline Aluminium A1050 & 20 & $65 \div 95$ & 69000 & 25900 & 0,33 \\
\hline Aluminium A5080 & 125 & $275 \div 350$ & 71000 & 26800 & 0,33 \\
\hline
\end{tabular}




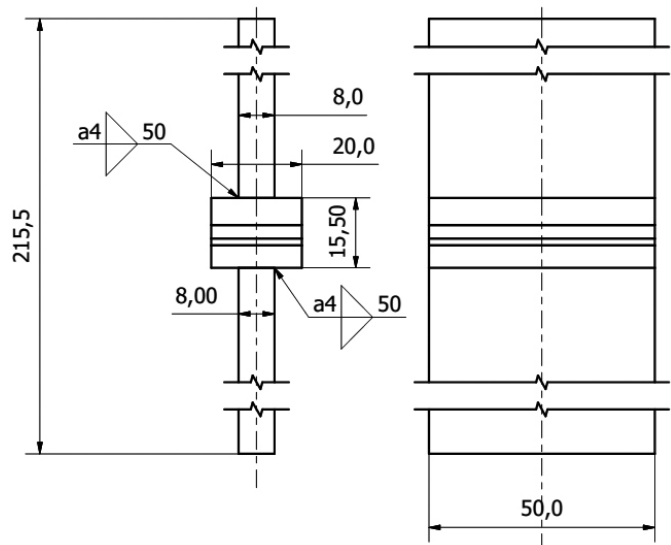

Rys. 5. Kształt i wymiary próbek w mm

Fig. 5. Specimen shape and dimensions in $\mathrm{mm}$ zastosowano sterowanie siłą (wymuszenie sinusoidalne). Za kryterium zniszczenia próbki uznawano przekroczenie przemieszczenia rejestrowanego przez czujnik maszyny o $20 \%$.

Wyniki badań eksperymentalnych zaprezentowano $\mathrm{w}$ formie tablicy II zawierającej parametry poszczególnych próbek oraz wyniki testów zmęczeniowych. Ze względu na krótkie części chwytowe próbka M3-2 uległa wyboczeniu podczas fazy początkowej testu.

Podczas testów prowadzono obserwację propagacji pęknięcia zmęczeniowego (rys. 6). Inicjacja pęknięć następowała w miejscach nieciągłości przetopu spoiny po stronie stali oraz aluminium. Ze względu na niższą w porównaniu do stali wytrzymałość stopu A5083 propagacja szczeliny następowała szybciej po stronie aluminium. W rezultacie rozwoju pęknięć zmęczeniowych konstrukcja łącznika nie osiągnęła trwałości na poziomie wymaganym przez zalecenia ABS, znacznie odbiegając od wymaganych 1000000 cykli. Deformacja konstrukcji łącznika, która została wywołana poprzez proces spawania, może również wpływać na trwałość zmęczeniową. Relatywnie niewielkie niedoskonałości kształtu łącznika wywołują działanie niekorzystnego momentu zginającego.

Tablica II. Własności mechaniczne badanych materiałów przed połączeniem

Table II. Mechanical properties of materials before cladding

\begin{tabular}{|c|c|c|c|c|c|c|c|c|}
\hline \multirow{2}{*}{ Lp. } & \multicolumn{8}{|c|}{ Parametry testów } \\
\cline { 2 - 9 } & $\mathbf{I}, \mathbf{m m}$ & $\mathbf{B}, \mathbf{m m}$ & $\mathbf{A}, \mathbf{m m}^{2}$ & $\mathbf{G}_{\mathbf{m}}, \mathbf{M P a}$ & $\mathbf{G}_{\mathbf{a}}, \mathbf{M P a}$ & $\mathbf{f}, \mathbf{H z}$ & $\mathbf{N}_{\mathbf{f}}$ & Uwagi $^{\prime}$ \\
\hline M3-2 & 20 & 50 & 1000 & $-46,5$ & 53 & 10 & - & Wyboczenie \\
\hline M3-3 & 20 & 50 & 1000 & $-46,5$ & 53 & 10 & 36000 & - \\
\hline M4-1 & 30 & 40 & 1200 & $-46,5$ & 53 & 5 & 17000 & - \\
\hline
\end{tabular}
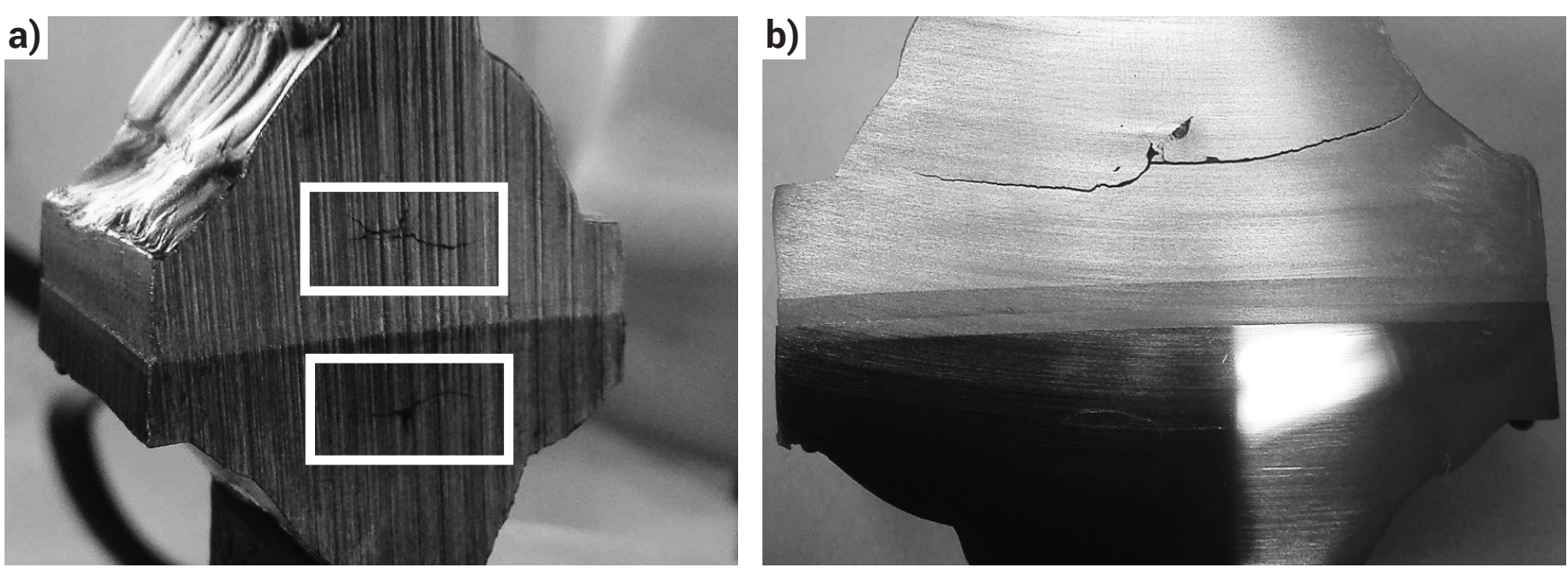

Rys. 6. Pęknięcia zmęczeniowe: a) w trakcie testu zmęczeniowego, b) pęknięcie po stronie aluminium

Fig. 6. Fatigue cracks: a) during the fatigue test, b) fatigue crack on the aluminum side

\section{Wnioski i spostrzeżenia}

Na podstawie przeprowadzonych badań sformułowano następujące wnioski i spostrzeżenia:

1. Trwałość zmęczeniowa łącznika spawalniczego zależy od parametrów uzyskanych spoin. Na trwałość zmęczeniową może wpływać również moment zginający generowany przez deformację łącznika.

2. Inicjacja pęknięć zmęczeniowych następowała w nieciągłościach przetopu spoiny. Propagacja postępowała po stronie stali i aluminium.

3. Nie zaobserwowano delimitacji złączy wykonanych metodą zgrzewania wybuchowego.

4. Trwałości zmęczeniowe łączników spawalniczych nie spełniały wymagań narzuconych przez zalecenia ABS. Udoskonalenie technologii spawania łączników może wpłynąć na podwyższenie odporności zmęczeniowej konstrukcji. 


\section{Literatura}

[1] Akbari-Mousavi S.A.A., Barrett L.M., Al-Hassani S.T.S.: Explosive welding of metal plates, Journal of Materials Processing Technology, 202, 2008, pp. 224-239.

[2] Crossland B.: Explosive welding of metals and its application, Clarendon Press, 1982.

[3] Findik F.: Recent developments in explosive welding, Materials \& Design, 32, 2011, pp. 1081-1093.

[4] Karolczuk A., Kowalski M.: Structural and Fatigue Properties of TitaniumSteel Bimetallic Composite Obtained by Explosive Welding Technology, Key Engineering Materials, 592-593, 2014, 594-597.

[5] Karolczuk A., Kowalski M., Bański R., Żok F.: Fatigue phenomena in explosively welded steel-titanium clad components subjected to push-pull loading, International Journal of Fatigue, 48, 2013, pp. 101-108.

[6] Król S., Bański R., Szulc Z., Gałka A.: Practical aspects of structural tests of titanium-steel bondsmade by explosive cladding and exposed to thermal proces loads, Advances in Material Science, 2007, pp. 50-56.
[7] Rozumek D., Bański R.: Crack growth rate under cyclic bending in the explosively welded steel/titanium bimetals, Materials \& Design, Vol. 38, No. 6, 2012, pp. 139-146

[8] Rules for the Classification of Ships, Part D Materials and Welding, RINA, Genova, 2012.

[9] ABS Guide For Fatigue Assessment Of Offshore Structures, American Bureau of Shipping, Huston, 2014

[10] Rules for the Manufacture, Testing and Certification of Materials, Lloyd's Register, Londyn, 2014.

[11] ABS Rules For Materials And Welding - Aluminum And Fiber Reinforced Plastics (Frp), American Bureau of Shipping, Huston, 2017.

[12] Approval of the Manufacturing Process of Metallic Materials, Bureau Veritas, Seine Cedex, 2017. 